TABLE Adjusted relative odds for any intraoperative complications by preoperative medical conditions

\begin{tabular}{lll}
\hline Condition & $\begin{array}{l}\text { Adjusted } \\
\text { relative odds }\end{array}$ & P value \\
\hline Asthma & 2.2 & 0.0007 \\
COPD & 2.2 & 0.0005 \\
Other respiratory & 1.9 & 0.0004 \\
MI < 6 months & 6.4 & 0.03 \\
MI $>$ 6 months & 1.1 & 0.76 \\
Hypertension & 2.2 & 0.0001 \\
Arrhythmia & 2.0 & 0.07 \\
CHF & 2.7 & 0.06 \\
Other cardiovascular & 1.2 & 0.53 \\
Cerebrovascular & 1.2 & 0.82 \\
Gastrointestinal & 2.7 & 0.0001 \\
Renal & 0.65 & 0.56 \\
\hline
\end{tabular}

would be "statistically significant"). We would suggest, instead, that future papers (not only in anaesthesia, but in all journal articles) should report actual $P$ values whenever possible and the reader can decide whether the association is meaningful or not.

Finally, we wish to make a few points about studies which employ non-randomized designs. First, randomized designs cannot be used to study "outcomes" of actual practice but can only be used to study specific research questions where groups of patients can be randomized. In attributing causal relationships one cannot use the results of only one study. ${ }^{2}$ The reader must consider the results of similar studies and look for similar trends and results. Only after a number of studies have been performed can the reader comfortably assume a true relationship between a variable or interest and a particular outcome. Thus we do not agree with the authors that one should ignore relationships and associations we have described, but to evaluate each on its own merits and compare the results with other such studies. Progress in science is seldom made when accepted observations are limited to those we already understand.

Having said this we do agree with the authors that this type of analysis is not definitive for comparing the quality of anaesthesia across hospitals. We confirmed that institutions are different, and that traditional methods used to assess outcome of care are not applicable to anaesthesia. We argue that other methods must be developed for the specialty.

How then should the three studies we reported be used? First, they should be used to inspire the advancement of methodology of assessing "quality" in anaesthesia. Second, individual rates of adverse outcomes may be interesting in themselves and prompt a critical examination of different practices that account for rate discrepancies. Third, risk factor profiles derived by such studies should allow practising clinicians to focus on those patients in their daily practise.

Marsha M. Cohen MD FRCPC

Clinical Epidemiology Unit

Sunnybrook Health Science Centre

and the Department of Health Administration

University of Toronto, Toronto, Ontario

Peter G. Duncan MD FRCPC

Department of Anaesthesia
Royal University Hospital

Saskatoon, Saskatchewan

REFERENCES

1 Duncan PG, Cohen MM, Tweed WA, et al. The Canadian four-centre study of anaesthetic outcomes: III. Are anaesthetic complications predictable in day surgical practice? Can J Anaesth 1992; 39: 440-8.

2 Hill $A B$. The environment and disease: association or causation? Proc Roy Soc Med 1965; 58: 295-300.

\section{Cost of soda lime}

To the Editor:

We found Dr. Dion's letter on calculating the cost of inhalational anaesthesia ${ }^{l}$ very interesting. According to his formulae, for a given percentage of vapour and for a given duration of anaesthesia, the cost varies directly with the fresh gas flow. This does not take into account the cost of consumption of soda lime at low fresh gas flows where rebreathing occurs. We would like to add to Dr. Dion's formulae accordingly. To do so the following additional information is required.

$\begin{array}{ll}\text { Cost (Sodasorb) } & 48.46 \mathrm{c} / 100 \mathrm{~g} \\ & \text { Sodasorb } \\ \mathrm{CO}_{2} \text { absorption capacity (Sodasorb) } & 45 \mathrm{~g} \mathrm{CO}_{2} / 100 \mathrm{~g} \\ & \text { Sodasorb }^{2}\end{array}$

Using the molar volume of gas at $21^{\circ} \mathrm{C}$ of 24.12 $\mathrm{L} \cdot \mathrm{mole}^{-1}$ and the molecular weight of $\mathrm{CO}_{2}$ of 44.009 $\mathrm{g} \cdot \mathrm{mole}^{-1}$, we calculate the cost of soda lime for complete rebreathing as follows:

$$
\mathrm{CS} \text { (cents) }=1.965 \dot{\mathrm{V}} \mathrm{CO}_{2} \mathrm{~T}
$$

where $\dot{\mathrm{V}} \mathrm{CO}_{2}$ is the $\mathrm{CO}_{2}$ production in $\mathrm{L} \cdot \mathrm{min}^{-1}$ and $\mathrm{T}$ is the duration of anaesthesia in minutes. The fraction of this that is rebreathed depends on the minute ventilation $(\dot{V})$ and the fresh gas flow $(\mathrm{F})$, both in $\mathrm{L} \cdot \mathrm{min}^{-1}$. For $F \geq \dot{V}$ one can assume that there is no rebreathing ${ }^{3}$ and obtain:

fraction of expired gas rebreathed $=1-\frac{F}{\dot{V}}$

The cost of soda lime as a function of flow is therefore;

$$
\begin{aligned}
\mathrm{CS} \text { (cents) } & =1.965 \dot{\mathrm{V}} \mathrm{CO}_{2} \mathrm{~T}\left(-\frac{\mathrm{F}}{\dot{\mathrm{V}}}\right) \\
& =-1.965\left(\frac{\dot{\mathrm{V}} \mathrm{CO}_{2}}{\dot{\mathrm{V}}}\right) \mathrm{TF}+1.965 \dot{\mathrm{VCO}}_{2} \mathrm{~T}
\end{aligned}
$$

Note that for $\mathrm{F} \geq \dot{\mathrm{V}}$, no soda lime is needed, so $\mathrm{CS}$ $=0$. 


\section{Cost of Halothane $0.77 \%$ and Soda Lime vs. Flow}

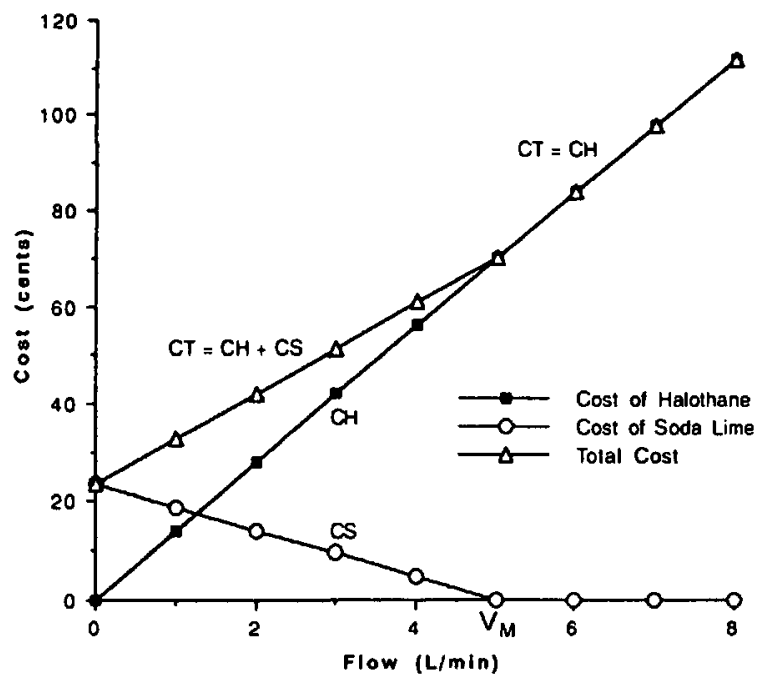

FIGURE I For a halothane concentration of $0.77 \%$, the total cost (CT), which is equal to the sum of the cost of halothane (CH) and the cost of soda lime (CS), is an increasing function of fresh gas flows for flows less than the minute ventilation (V). This is because as fresh gas flow increases, the cost of halothane increases faster than the cost of soda lime decreases. For flows greater than or equal to the minute ventilation, the total cost equals the cost of halothane.

Converting Dr. Dion's equation for halothane cost from dollars to cents, we obtain the cost of halothane $(\mathrm{CH})$ as a function of fresh gas flow, where $P$ is the vaporizer concentration of halothane is percent:

$\mathrm{CH}$ (cents) $=\frac{\text { PTF }}{3.31}$

Upon adding the equations for $\mathrm{CS}$ and $\mathrm{CH}$, we obtain the total cost (CT) for $\mathrm{F}<\dot{\mathrm{V}}$ :

$$
\begin{aligned}
\mathrm{CT} \text { (cents) } & =\mathrm{CS}+\mathrm{CH} \\
& =\left(\frac{\mathrm{P}}{3.31}-\frac{1.965 \dot{\mathrm{V} C O}_{2}}{\dot{\mathrm{V}}}\right) \mathrm{TF}+1.965 \dot{\mathrm{V}} \mathrm{T}
\end{aligned}
$$

For $\mathrm{F} \geq \dot{\mathrm{V}}, \mathrm{CT}=\mathrm{CH}$

For example, if one substitutes the values of $\mathrm{V}_{\mathrm{CO}_{2}}=$ $0.2 \mathrm{~L} \cdot \mathrm{min}^{-1}, \dot{\mathrm{V}}=5 \mathrm{~L} \cdot \mathrm{min}^{-1}, P=0.77 \%$ halothane (1 MAC) and assumes a $60 \mathrm{~min}$ anaesthetic, one obtains:

$$
\mathrm{CH}=13.958 \mathrm{~F}
$$

$\mathrm{CS}=-4.716 \mathrm{~F}+23.58$

$\mathrm{CT}=9.242 \mathrm{~F}+23.58$ for $\mathrm{F}<5, \mathrm{CT}=13.958 \mathrm{~F}$

for $F \geq 5$

(Figure 1)

Note that in Figure 1 the total cost curve below $\dot{V}$ is an increasing function of flow because, as flow increases,

\section{Cost of Halothane $0.15 \%$ and Soda Lime vs. Flow}

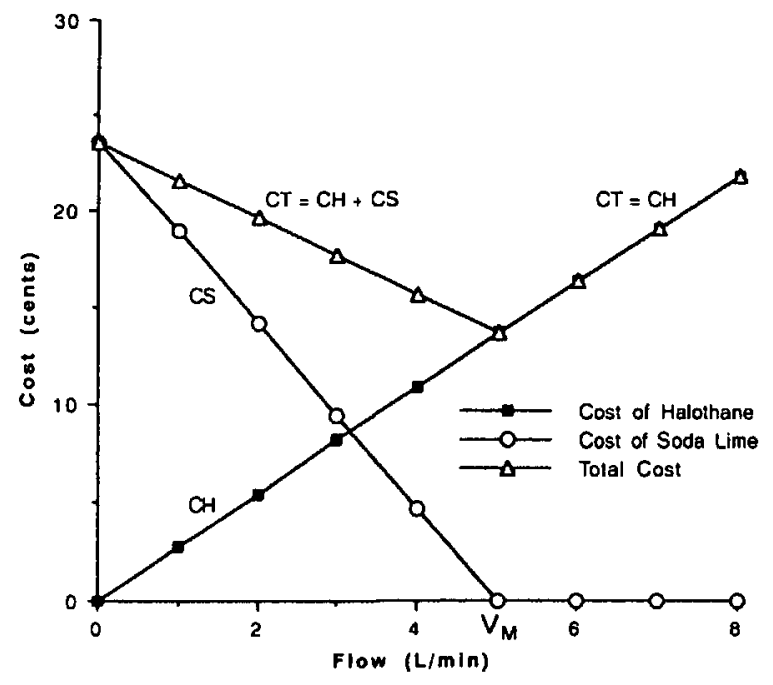

FIGURE 2 For a halothane concentration of $0.15 \%$, the total cost (CT), which is equal to the sume of the cost of halothane $(\mathrm{CH})$ and the cost of soda lime (CS), is a decreasing function of fresh gas flows for flows less than the minute ventilation ( $\dot{\mathrm{V}}_{\mathrm{M}}$ ). This is because as fresh gas flow increases, the cost of soda lime decreases faster than the cost of halothane increases. For flows greater than or equal to the minute ventilation, the total cost equals the cost of halothane.

the cost of halothane increases faster than the cost of soda lime decreases. This would not be true for low halothane concentrations. In fact, from the equation for $\mathrm{CT}$, it can be seen that this is only true if:

$\frac{\mathrm{P}}{3.31}-\frac{1.965 \dot{\mathrm{V}} \mathrm{CO}_{2}}{\dot{\mathrm{V}}}$

$P>6.504 \frac{\mathrm{VCO}_{2}}{\dot{\mathrm{V}}}$ or $P>0.260 \%$

assuming $\dot{\mathrm{V}} \mathrm{CO}_{2}=0.200 \mathrm{~L} \cdot \mathrm{min}^{-1}$ and $\dot{\mathrm{V}}=5.0 \mathrm{~L} \cdot \mathrm{min}^{-1}$

The practical result is that for the levels of $\mathrm{VCO}_{2}$ and $\dot{V}$ defined above and concentrations of halothane below the critical concentration of $0.260 \%$, total cost will decrease until the flow reaches minute ventilation, and will then follow the halothane cost curve (Figure 2). It will be most economical to use a fresh gas flow equal to the minute ventilation. This of course does not take into account the cost of oxygen and nitrous oxide.

Similar calculations can be used to obtain the critical concentrations for enflurane and isoflurane as follows:

Enflurane $P>0.766 \frac{\dot{\mathrm{V}} \mathrm{CO}_{2}}{\dot{\mathrm{V}}}$,

which is $0.031 \%$ using the above assumptions. 
Isoflurane $P>0.452 \frac{\dot{\mathrm{V}} \mathrm{CO}_{2}}{\dot{\mathrm{V}}}$

which is $0.018 \%$ using the above assumptions

It can be seen that for enflurane and isoflurane, the total cost will always be an increasing function of fresh gas flow, because their critical concentrations are far below clinically useful concentrations.

Leonard B. Eisen MD FRCPC

Joseph A. Fisher MD FRCPC

University of Toronto

Mount Sinai Hospital Department of Anaesthesia

Toronto, Ontario

\section{REFERENCES}

1 Dion, $P$. The cost of anaesthetic vapours. Can J Anaesth 1992; 39: 633.

2 The Sodasorb Manual of Carbon Dioxide Absorption. Fifth printing: W.R. Grace \& Co., Dewey and Almy Chemical Division 1986: 22.

3 Dorsch $J A$, Dorsch $S E$. Understanding Anaesthesia Equipment. 2nd ed. Baltimore: Williams \& Wilkens, 1984: 138.

\section{$R E P L Y$}

I am most grateful for this letter. The authors have taken a formula strictly limited to the calculation of the cost of the halogenated agents and used it to ask another question. What is the cheaper way to prevent rebreathing of $\mathrm{CO}_{2}$ run rapid flows of fresh gas, or mop it up with soda lime and reduce vapour costs?

At equivalent MAC levels, halothane, enflurane, and isoflurane cost in the ratio of 1,19 , and 22. The authors have found that for the two more expensive agents, it is always cheaper to run low flows and consume soda lime. They have elegantly calculated that if you run the cheapest agent, halothane, at 1/3 MAC or lower, you can save money by having a flow rate equivalent to the minute ventilation.

All of us have ignored the cost of oxygen and nitrous oxide. I ignored it because I was mainly interested in comparing narcotic versus vapour costs, where the nitrous and oxygen costs would be similar.

In the extended analysis above, it is interesting to consider the oxygen and nitrous costs.

Oxygen is cheap. At about 20 to 25 cents per thousand litres, in the hypothetical anaesthetic given above, even at $5 \mathrm{~L} \cdot \mathrm{min}^{-1}$, the oxygen cost would be only two or three cents.

I have been surprised to discover that nitrous oxide is actually quite expensive, costing some 50 to 60 dollars for about 30 kilograms of liquid. This works out to about one third of a cent per litre of gaseous nitrous oxide. If 200 of the 300 litres of fresh gas flow in the hypothetical example above were nitrous oxide, this would cost 67 cents roughly, in other words, the nitrous oxide would cost as much as the halothane (even at $0.77 \%)$.
So what Drs. Eisen and Fisher might add is another linear term to their total cost $C T$, which would be $C N$, the cost of the nitrous oxide, where

$C N($ cents $)=F T P n / 3$

and $P n$ is the proportion of fresh gas that is nitrous oxide, usually about 0.7 in most anaesthetics.

This is a big term. It lowers the "critical concentration" of halothane, below which a negative slope for $F<\dot{V}$ is seen, to about $0.03 \%$, away below a clinically useful concentration.

Hence putting all this together, we see that to save money, it is cheaper to run gas flows as low as possible, in essentially all situations, and to use halothane.

P. Dion

Department of Anaesthesia

St. Catherine's General Hospital

Ontario

\section{An accidental subdural injection of a local anaesthetic resulting in respiratory depression}

To the Editor:

Accidental subdural block is a rare complication of epidural anaesthesia. The most common feature is an unexpectedly wide spread of sensory block, which is not usually accompanied by apnoea. ${ }^{1}$ We report a case in which life-threatening respiratory depression was observed immediately after large doses of a local anaesthetic had been injected accidentally into the subdural space.

A 19-year-old, 81-kg man was scheduled for a knee ligament reconstruction under a lumbar epidural anaesthesia. He had no anaesthetic history. A 17-ga Tuohy needle was inserted at $\mathrm{L}_{2 / 3}$, and a closed-ended multiorifice catheter was passed although slight resistance was noted. After a negative aspiration and a negative test dose of a $3 \mathrm{ml}$ lidocaine $1.5 \%$ with epinephrine, $12 \mathrm{ml}$ of the solution was injected which produced an area of analgesia from $\mathrm{T}_{6}$ to $\mathrm{T}_{12}$. Fifteen minutes later, $10 \mathrm{ml}$ lidocaine $2 \%$ were added. Since the area of sensory loss did not extend to the lumbar dermatome, the patient was placed into the decubitus position for a spinal anaesthesia, but then he complained of dyspnoea. In the supine position, his lips and nails showed signs of cyanosis. Ventilation with $\mathrm{O}_{2}$ was started and the cyanosis disappeared, but he was still unable to breathe or phonate. The BP did not decrease below $100 \mathrm{mmHg}$ at any stage although $5 \mathrm{mg}$ of ephedrine was administered prophylactically. Because the events seemed to be compatible with an accidental subtotal spinal block, general anaesthesia was induced and the trachea was intubated. The operation 